Journal of The Magnetics Society of Japan Vol. 13, Supplement, No. S1 (1989) (C) 1989 by The Magnetics Society of Japan

\title{
HI SATURATION FE ALLOY FILMS DEPOSITED ON NON-MAGNETIC UNDERLAYERS WITH PREFERRED CRYSTAL ORIENTATION
}

Yutaka SHIMADA, Akihiko HOSONO and Masayuki KOIDE

Research Insitutue for Scientific Measurements, Tohoku Univ., Katahira 2-1-1, Sendai 980, Japan

\begin{abstract}
FeSi alloys films with low magnetostriction were deposited on $\mathrm{Si}_{2}, \mathrm{Zn} 0$ and $\mathrm{Mg} 0$ underlayers and magnetic softness and thermal stability were measured.

The best results were obtained for the films on $\mathrm{Mg} 0$. The films on $\mathrm{MgO}$ have the smallest crystal size and subsequently the lowest Hc. Double layer films on $\mathrm{MgO}$ showed lowest Hc and best thermal stability.
\end{abstract}

\section{Introduction}

Polycrystalline $\mathrm{Fe}$ alloy films with magnetic softness is of interest because of their high saturation magnetization.

In order to obtain magnetic softness in thin films, very weak crystalline anisotropy and low magnetostriction are generally required. But $F e$ polycrystalline alloy films with high saturation magnetizatio do not satisfy the above conditions.

However, various Fe alloy films with low Hc have been reported recently. Their low Hc are attributed to the microcrystalline structures which are brought about by various film deposition conditions, such as radiation of $\mathrm{Ar}$ ion beam to the film surface during deposition ${ }^{(1)}$, or introducing $\mathrm{N}_{2}$ gas to suppress crystal growth. Another method to obtain magnetic softness is to deposit different materials alternatively (2).

However, all of those films suffer from thermal instability of magnetic softness due to crystal growth or atomic diffusion at relatively low temperatures.

The authors have been studying crystal structures and magnetic softness of $\mathrm{Fe}$ alloy films deposited on various non-ferromagnetic underlayers. These underlayers are favorable to the thermal stability of magnetic softness since they controll crystal growth of $\mathrm{Fe}$ alloy films and sometimes suppresses further crystal growth.

High satruation magnetization FeSi films with $\mathrm{Si}$ content up to $8 \mathrm{wt} \%$ deposited on $\mathrm{Zn} 0$ was studied previously(3). The films show lower Hc for $2 \sim 3$ wt\$Si where the macroscopic magnetostriction becomes zero. They show much lower Hc when they are double layered. Reason for the improvemnt of magnet ic softness is probably due to magnetostatic interactions of the crystals through the thin intermeidate films. This may bring about an effect similar to that of the interaction between the grains when the films are in a microcrystlline state(4).

Since various factors such as multilaying effect, microcrystalline structure and macroscopic magnetostriction affect the softness of high saturation films, it is usually difficult to find out how to make further improvements.

Here, some experiments on and $\mathrm{Fe}-7 \sim 8$ w $\%$ Si films with intrinsically low magnetost- 
riction deposited on $\mathrm{SiO}_{2}, \mathrm{ZnO}$ and $\mathrm{MgO}$ are described. The purpose of the experiemnt is to obtain better understanding of the effect on the crystal structure, and subsequently on thermal stability of magnetic softness without influence from magnetostriction, and multilaying effect using those films as intermediate films is studied.

\section{Experiments}

The samples were deposited by ion beam sputtering and by D.C.magenetron sputtering. Since sputtering was made in pure Ar atomosphere,some deficiency of oxygen in the oxide films were detected by Augier spectroscopy, although clear Xray peaks corresponding to $\mathrm{Zn0}$ or $\mathrm{Mg} 0$ were observed.

Film thickness is about $1000 \mathrm{~A}$ for magnetic and Xray measurements. The films with this thickness were selected since they show good orientation of crystal growth and as a function of thickenss Hc exhibits minimum at about $1000 \mathrm{~A}$. Substrate tem- perature was set at $300^{\circ} \mathrm{C}$ or $400^{\circ} \mathrm{C}$ depending on the growth condition of the underlayers. Saturation magnetostriction measured for a few samples is in the range $1 \sim 3 \times 10^{-6}$ for 7 $\sim 8 \mathrm{wt} . \% \mathrm{Si}$. The calculation based on the bulk data predicts $1 \sim 2 \times 10^{-6}$ for $7 \mathrm{wt} . \$ \mathrm{Si}$ and $0 \sim$ $-2 \times 10^{-6}$ for $8 w t . \% S i$. The difference may be due to imcomplete formation of $\mathrm{DO}_{3}$ structure in the films.

The films were annealed in an external field of $3000 \mathrm{e}$ for $30 \mathrm{~min}$. at each temperature.

\section{Results}

Figure 1 shows Xray diffraction patterns of $\mathrm{Fe}-7 \mathrm{wt} . \% \mathrm{Si}$ film deposited on $\mathrm{SiO}_{2}, \mathrm{ZnO}$ and $\mathrm{MgO}$. $\mathrm{Zn0}$ underlayer exhibits preferred growth of (002) parallel to the film plane and $\mathrm{FeSi}$ deposited on it exhibits preferential growth of (110). Mg0 underlayer exhibits preferred growth of $(100)$ and FeSi on it shows growth of (100) plane. For-
Figure 1

Variation of Xray diffraction patterns by annealing for FeSi films deposited on various underlayers.

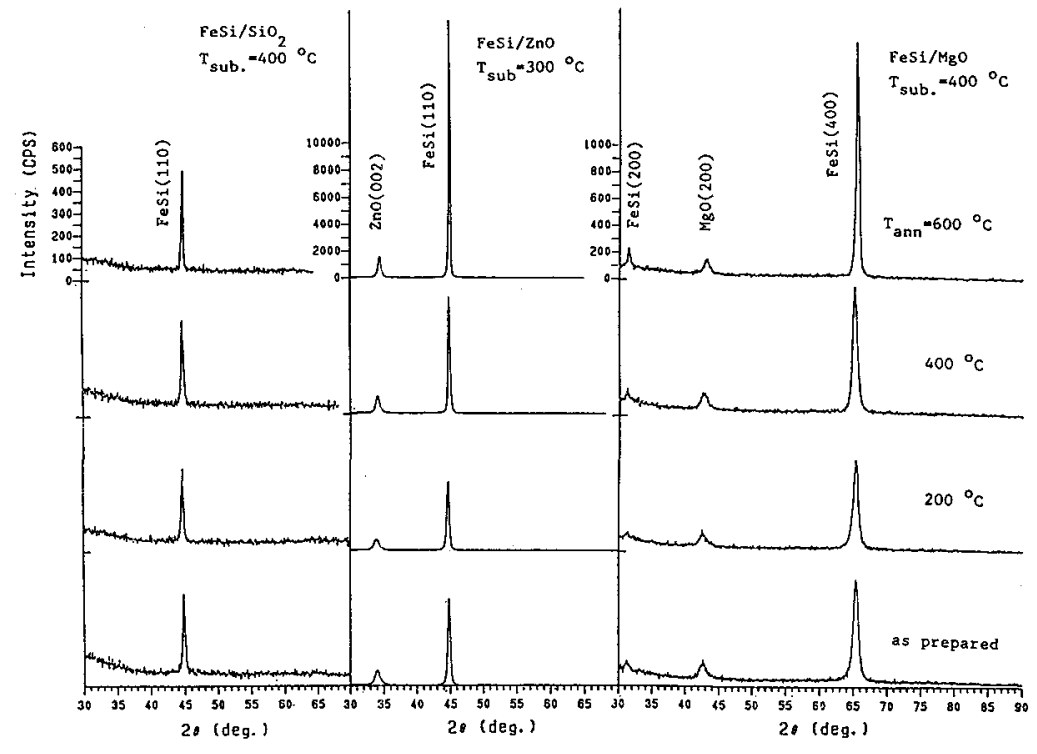


mation of $\mathrm{DO}_{3}$ phase is indicated by (200) in the pattern. Since ratio of $(400)$ to (220) is about 0.2 for FeSi with isotropic crystal structure, relatively intensive peak from (400) means the film has well oriented growth of $(100)$ planes. The film on $\mathrm{SiO}_{2}$ shows weak (110) peak indicating it is closest to the isotropic crystal structure among these three samples. As seen in the figure the preferential grwoth is more enhanced by annealing.

Figure 2 shows variation of the crystal size estimated from the width of the peaks from the oriented planes. It should be noted that the film on Mg0 has relatively small grain size and even after annealing at $600{ }^{\circ} \mathrm{C}$ crystal growth seems to be suppressed.

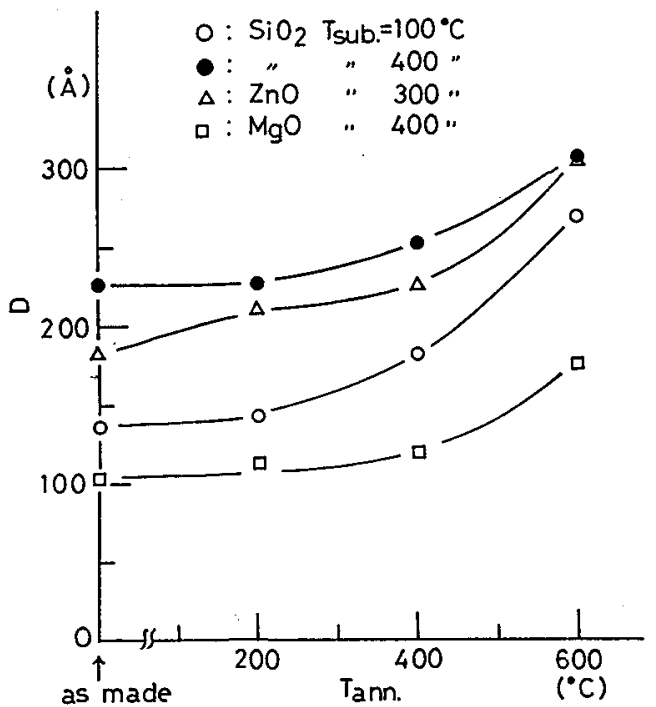

Figure 2

Variation of the crystal size by annealing for FeSi films deposited on various underlayers.
Figure 3 shows variation of hc for the films on $\mathrm{SiO}_{2}, \mathrm{ZnO}$ and $\mathrm{MgO}$ by annealing. The film on MgO shows lowest Hc. This agrees with the result in Fig. 2 where the film on Mg0 has the smallest grain size.

Figure 4 shows variation of $\mathrm{Hc}$ for double layer films with $\mathrm{SiO}_{2}$ and $\mathrm{ZnO}$ as underlayer and intermediate layers. The multilayer structure of the former is $\mathrm{SiO}_{2} / \mathrm{FeSi}(900 \mathrm{~A})$ $/ \mathrm{SiO}_{2}(80 \AA) / \mathrm{FeSi}(900 \mathrm{~A}) / \mathrm{SiO}_{2} /$ (sapphire sub.). Two kinds of multilayer structure were studied for the latter. One of them is $\mathrm{SiO}_{2} /$ $\mathrm{FeSi}(900 \mathrm{~A}) / \mathrm{Zn0}(40 \mathrm{~A}) / \mathrm{SiO}_{2}(40 \mathrm{~A}) / \mathrm{FeSi}(900 \mathrm{~A})$ $/ \mathrm{SiO}_{2} /$ (sapphire sub.) (denoted by $\mathrm{A}$ in the figure) and the other is $\mathrm{SiO}_{2} / \mathrm{FeSi}(900 \mathrm{~A}) / \mathrm{ZnO}$ (80A)/FeSi $(900 \mathrm{~A}) / \mathrm{SiO}_{2} /$ (sapphire sub.)

(denoted by $B$ in the figure). The difference is that the former has double intermediate layers. The reason is that $\mathrm{ZnO}$ shows good orientation of (002) on $\mathrm{SiO}_{2}$ but becomes amorphous like on $\mathrm{Fe}$ surface. Here softness of these two kinds of double layer struc-

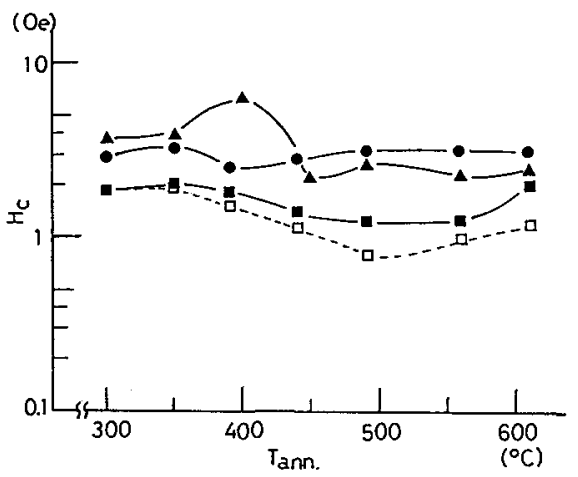

Figure 3

Variation of Hc by annealing for FeSi films deposited on various underlayers.

$$
\begin{aligned}
& \mathrm{O}: \mathrm{SiO}_{2} / \mathrm{FeSi} / \mathrm{ZnO} / \mathrm{SiO}_{2} / \mathrm{sub} \text {. } \\
& \times: \mathrm{SiO}_{2} / \mathrm{FeSi} / \mathrm{SiO}_{2} / \mathrm{sub} \\
& \mathrm{a}: \mathrm{SiO}_{2} / \mathrm{FeSi} / \mathrm{MgO}_{\mathrm{SiO}} / \mathrm{sub} \text {. (e.a.) } \\
& \square: \text { (h.a.) }
\end{aligned}
$$


tures is studied.

It is clearly seen in Fig. 4 that for sample B Hc increases continuously as the annealing temperature increases while sample A shows good thermal stability. Xray diffraction intensity from (110) is always weaker for $B$ than $A$ but the ratio of the intensity is not reproducible. The film with $\mathrm{SiO}_{2}$ intermediate layer shows less stable Hc. Similar experiments on $\mathrm{MgO}$ are shown in Figure 5. Sample A has a double layer intermediate structure $\mathrm{HgO}(40 \mathrm{~A}) / \mathrm{SiO}_{2}(40 \mathrm{~A})$ and sample $\mathrm{B}$ has a single layer $\mathrm{MgO}(80 \mathrm{~A})$. Little difference of $\mathrm{Hc}$ is seen for those samples. Xray diffraction intensity from (001) is about the same for those samples.

\section{Discussions}

In the present experiment influence of underlayer and intermediate layer to crystal growth in $\mathrm{FeSi}$ and subsequent change of $\mathrm{Hc}$ was studied.

On ZnO underlayer FeSi films show good growth of (110) and relatively large crystal size. This is effective to stabilize the macroscopic magnetostriction. In a study of FeNi films on $\mathrm{ZnO}$ it was found that the macroscopic magnetost-riction is almost constant aginst annealing up to $600{ }^{\circ} \mathrm{C}$.Since the saturation magnetostriction is low for the present samples, the dominant factor to determine the softness may be crystal size and , as seen in Fig. 3, the sample on $\mathrm{MgO}$ has the smallest crystal size resulting in lower and more stable Hc.

Another advantage of $\mathrm{MgO}$ is that $\mathrm{MgO}$ layer shows good orientation of (001) even on FeSi surface. This means that ith combination of Fe alloy and $\mathrm{MgO}$ it may be possible to fabricate films with finer multilayer structure with smaller crystal size without deteriorating thermal properties.

Slight increase of Hc after annealed at $600^{\circ} \mathrm{C}$ as seen in Fig. 4 and 5 may be explained by rapid increase of the crystal size as observed in Fig. 1 and 2, which

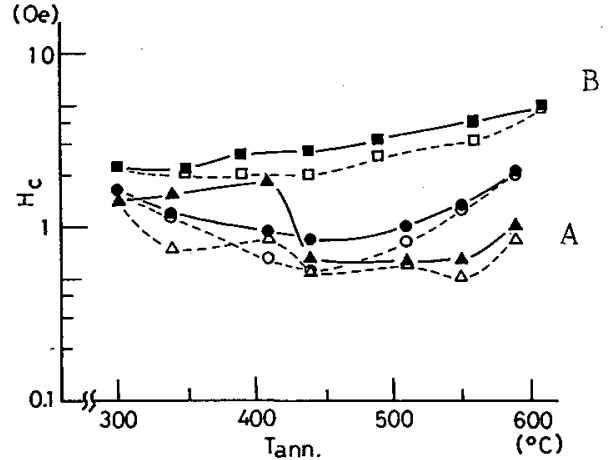

Figure 4

Variation of Hc for multilayered FeSi films deposited on $\mathrm{ZnO}$.
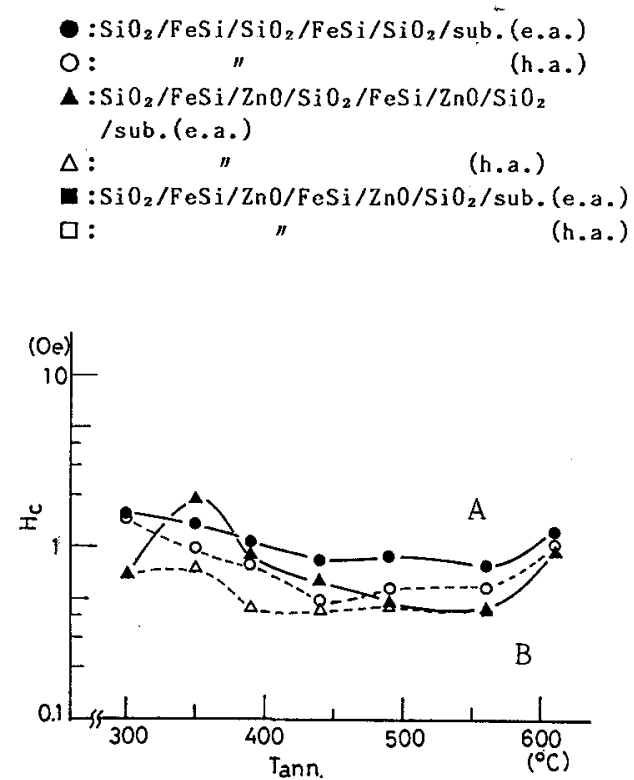

Figure 5

Variation of Hc for multilayered FeSi films deposited on $\mathrm{MgO}$.

- $: \mathrm{Si}_{2} / \mathrm{FeSi} / \mathrm{Mg} 0 / \mathrm{SiO}_{2} / \mathrm{FeSi} / \mathrm{MgO} / \mathrm{SiO}_{2}$ /sub.(e.a.)

$0: "$ (h.a.)

$\triangle: \mathrm{SiO}_{2} / \mathrm{FeSi} / \mathrm{Mg} 0 / \mathrm{FeSi} / \mathrm{MgO} / \mathrm{SiO}_{2}$ /sub. (e.a.)
$\triangle:$
(h.a.) 
cannot be overcome by the magnetostatic interaction between the crystals through the intermediate layers.

Conclusion

Magnetic softness and its thermal stability for single and double layer FeSi films deposited with $\mathrm{SiO}_{2}, \mathrm{ZnO}$ and $\mathrm{MgO}$ under and intermediate layers was studied. Since FeSi films has intrinsically low magnetostriction, it was clarified that $\mathrm{MgO}$ layer is the most effective to maintain low Hc.

Experiments on magnetic softness and thermal stability of FeNi films with macroscopically low magnetostriction deposited on $\mathrm{MgO}$ is in progress.

References

(1) N.Ishiwata,C.Wakabayashi and T. Hatsumoto , IEEE Trans. Magn. vol.24,3078(1988).

(2) Y.Nagai,M.Senda and T.Toshina,J.Appl. Phys., 63,1136(1988).

(3) Y.Shimada, IEEE Trans. Magn. vol.24,3075 (1988).

(4) H.Hof fmann, J.Appl.Phys., 35, 1790 (1964). 